much bigger payloads farther from Earth.

The first launch for Falcon 9, whose nine engines have been successfully fired on the ground, is slated for next year.

For a longer version of this story, see http:// tinyurl.com/43gnya.

\section{Carbon dioxide emissions rise to record levels}

Carbon dioxide emissions from fossil fuels and cement manufacturing are rising faster than the worst-case scenario drawn up by the Intergovernmental Panel on Climate Change (IPCC). According to the latest worldwide carbon budget, released by the Global Carbon Project, $\mathrm{CO}_{2}$ levels rose by $3.5 \%$ a year between 2000 and 2007, compared with $2.7 \%$ as calculated by the IPCC. During the $1990 \mathrm{~s}$, emissions rose at $0.9 \%$ a year.

"For a decade we've been using the [IPCC] middle-ground scenario, while we're actually in a different realm of emissions," says Pep Canadell, the project's executive director.

China is now the biggest emitter of $\mathrm{CO}_{2}$ and responsible for $21 \%$ of the world's emissions - up from $14 \%$ in 2002 . This knocks the United States into second place, contributing $19 \%$ of global emissions. India is fourth, but looks set to take third place from Russia this year.

\title{
China's first spacewalk
}

Zhai Zhigang (pictured), the commander of the three-person Shenzhou VII spacecraft, has become the first Chinese astronaut, or 'taikonaut', to spacewalk. Zhai spent 13 minutes outside the orbital module on 27 September.

A fire alarm went off while he was conducting the spacewalk, but it turned out to be due to a faulty sensor. Zhai retrieved a rack containing lubricant samples from outside the spacecraft.

The mission landed in Mongolia on 28 September.

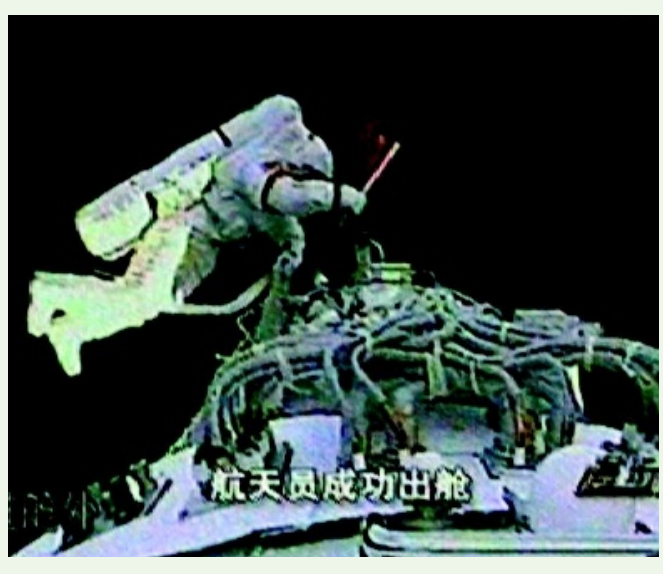

\section{US Congress approves funding bill for science}

Most US science agencies will see their budgets frozen at 2008 levels under a massive $\$ 630$-billion spending bill that was passed by Congress on 27 September. The 'continuing resolution' keeps the government operating until March 2009, when a new president and new Congress will tackle funding priorities.

A few agencies did get new dollars for 2009. Science and technology funding within the Department of Defense, for instance, rose 7\%, and research and development funding at the
Department of Homeland Security rose $9 \%$. The bill also provides NASA with permission to buy flights on Soyuz spacecraft from Russia until 2016, in order to ferry astronauts and cargo to the International Space Station after the space shuttle is retired.

\section{Corrections}

In the News Feature 'The fate of fingers' (Nature $455,160-164 ; 2008)$, we misspelled the name of Matthew Porteus of the University of Texas: apologies. In the News Feature 'Postmodern evolution?' (Nature 455, 281-284; 2008), we should have identified Susan Mazur as the first to use the term 'The Woodstock of Evolution' to describe the Altenberg meeting. 